\title{
A obra de câmara de Jorge Peixinho
}

FRANCISCO MONTEIRO

Escola Superior de Educação/P.PORTO (franciscomonteir@gmail.com)

\section{Introdução}

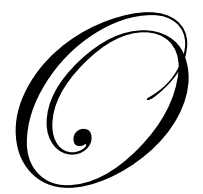

presente estudo advém fundamentalmente de um projeto de investigação alargado, dedicado à Edição Crítica da Obra de Câmara de Jorge Peixinho (J.P.). Este projeto foi subsidiado pela F.C.T. (Fundação para a Ciência e Tecnologia, Portugal), inserido no C.E.S.E.M. (Centro de Estudos em Sociologia e Estética Musical, Universidade Nova de Lisboa, Faculdade de Ciências Sociais e Humanas) (C.E.S.E.M., 2012).

Pretende-se uma reflexão sobre a totalidade da obra de câmara de Jorge Peixinho (J.P.), numa perspetiva global, informada através do estudo dos manuscritos digitalizados presentes no Centro de Investigação \& Informação da Música Portuguesa e no C.E.S.E.M., através de partituras (PEIXINHO, 1999), (PEIXINHO, 2004), e através de catálogos atualizados e analisados criticamente, da edição crítica de obras já realizada, e de estudos parciais, dos quais se salientam estudos críticos sobre a obra para piano e sobre a obra vocal, sobre o G.M.C.L. (Grupo de Música Contemporânea de Lisboa), sobre os escritos e o pensamento de J.P., e trabalhos de pesquisa de investigadores como Mário Vieira de Carvalho (CARVALHO, 1998), Evgueni Zoudilquine (ZOUDILKINE, 2002), Francisco Monteiro (MONTEIRO, 2003), (MONTEIRO, 2015), Cláudia Vasconcelos Borges (BORGES, 2005), Cristina Delgado Teixeira (DELGADO TEIXEIRA, 2006), Ana Telles (TELLES, 2012), Paulo Assis (ASSIS, 2012), Pedro Taveira (TAVEIRA, 2012), etc.

\section{Jorge Peixinho: um retrato}

A personalidade de J.P.é das mais salientes na música portuguesa da segunda metade do séc. XX. Trata-se de um homem que marcou todos os que contactou, de um lutador político contra o regime de Salazar e Caetano, de um defensor de uma estética de choque, de vanguarda, contra um conservadorismo burguês reinante em Portugal, de um homem de cultura atento às múltiplas transformações que observava, enfim de um músico multifacetado em diversas ordens: 
a) 0 pianista, tocando a solo e em formações de câmara obras de Liszt, Debussy, Schönberg, Webern, Stockhausen, Cage e dos seus contemporâneos, atividade que manteve até ao fim da sua vida;

b) 0 compositor, com uma vasta obra tocada e gravada, com apresentações em Portugal, França, Itália, Alemanha e em diversas cidades e festivais do Brasil; saliente-se a sua participação em Darmstadt (desde 1963);

c) 0 divulgador de música contemporânea, através de cursos específicos (desde 1964) e de comentários a concertos seus e alheios (tal como no concerto de K. Stockhausen em Lisboa, em 1961); e divulgador da música portuguesa além-fronteiras, dando a conhecer novos compositores da sua geração;

d) 0 maestro e diretor artístico, dirigindo o G.M.C.L. - Grupo de Música Contemporânea e Lisboa - que fundou em 1970 e do qual foi o mentor fundamental;

e) O professor e formador de composição e análise, nos Conservatórios do Porto (anos 60) e de Lisboa (anos 80 e 90) e através de cursos de formação contínua para professores;

f) 0 artista participante da evolução cultural desde o início dos anos 60, participando dos primeiros happenings em Portugal, colaborador e amigo de múltiplos artistas plásticos, poetas, cineastas e músicos em Portugal e no Brasil, tais como Ernesto de Sousa, Ana Hatherly, E. M. de Melo e Castro, Mário Falcão, Salette Tavares, Gilberto Mendes, H. J. Koellreutter, etc.

Estas diferentes carreiras e perspectivas de J.P. decorreram de forma interligada e coerente, numa vida repleta de desafios, de vontades e de impulsos, não havendo aparentemente contradições ou antagonismos no seu percurso.

\section{Jorge Peixinho e o Brasil}

A ligação de Jorge Peixinho ao Brasil desenvolveu-se em múltiplos contactos e momentos, iniciados em Darmstadt nos cursos de 1968: o contacto e a comunhão de ideias com Gilberto Mendes nesses cursos fizeram desenvolver uma amizade e 
camaradagem inicialmente epistolar e depois pessoal. A primeira viagem de J.P. ao Brasil foi em 1970, para participar no Festival de Música de Curitiba, apresentandose também em São Paulo e Santos; nesse mesmo ano regressa para o II Festival de Música de Guanabara, Rio de Janeiro. (PASCOAL, 2012, PESSANHA DE MENEZES, 2016). Logo apareceram entrevistas em jornais portugueses e brasileiros: Vida Mundial 6/3/1970, O Globo 7/5/1970, Estado de S. Paulo, suplemento literário, 23/5/1970 (ASSIS, 2010). E, na sequência de tão frutuosos contactos, há a possibilidade de J.P. emigrar para o Brasil e leccionar na Universidade de Brasília. Como investigou Pessanha de Menezes (PESSANHA DE MENEZES, 2016), tal vontade não se veio a realizar por dificuldades financeiras, tal como referido em carta pelo Chefe do Departamento de Música da Universidade de Brasília, Conrado José de Marco. J.P. voltou ao Brasil ainda em 1978, 1982, 1984, 1985, 1986, 1990, 1991 e 1994 (PESSANHA DE MENEZES, 2016), desenvolvendo contactos com múltiplos compositores e intérpretes brasileiros.

Algumas obras de câmara de J.P. têm uma referência clara no Brasil, tal como Villalbarosa... homenagem a Villa-Lobos de 1987, peça para piano solo dedicada a Gilberto Mendes. Mas da maior relevância é a obra Greetings, Lied für H. J. K, terminada, segundo o manuscrito, a 7 de dezembro de 1984, para mezzo-soprano, flauta, fagote, violoncelo e percussão. J.P., em 1984, recebe um convite da cantora alemã/brasileira Margarita Schack para compor uma obra para o $70^{\circ}$ aniversário do seu companheiro, o compositor Hans Joachim Koellreutter (1915-2005). Esta obra, algo definidora de muitas características musicais e interpessoais do compositor, foi estreada pelo Grupo Juntos Música Nova, gravada e editada em 1986 na colecção PRO-MEMUS (Ministério da Cultura - Funarte), com o nome Koellreutter 70 (TAVEIRA, 2012).

\section{A Obra Câmara de 1 a 5 instrumentos: uma perspectiva geral do corpus}

A obra de J.P. é bastante vasta: cerca de 173 peças para diferentes grupos, incluindo diferentes versões da mesma obra. Tendo sido necessário colocar alguns limites para o projeto de Edição Crítica das Obras de Câmara, optou-se por estabelecer o limite máximo de 5 instrumentos. 0 corpus é, ainda, bastante vasto: 
cerca de 95 peças, incluindo versões diversas (para diferentes instrumentos, recomposições e reelaborações).

Apresenta-se aqui a lista total, considerando os códigos dos manuscritos presentes no catálogo de José Machado (MACHADO, 2002) e aferidos no projeto acima referido (C.E.S.E.M., 2012), o ano de composição, o título, o número de instrumentos e de vozes. Refira-se, desde logo, diferentes versões (algumas incompletas) de algumas obras.

\begin{tabular}{|c|c|c|c|c|}
\hline Código & Ano & Obras & $\begin{array}{c}\text { Total de } \\
\text { Instrumentos }\end{array}$ & $\begin{array}{c}\text { Total de } \\
\text { Vozes }\end{array}$ \\
\hline JP001 & 1959 & Cinco Pequenas Peças para Piano & 1 & 0 \\
\hline JP002 & 1959 & Due Expressioni & 2 & 0 \\
\hline JP003 a & 1959 & Fascinação & 2 & 1 \\
\hline JP003 b & 1959 & Fascinação & 2 & 1 \\
\hline JP009 III a & 1959 & $\begin{array}{c}\text { Ah! A angústia, a raiva vil, o } \\
\text { desespero...a }\end{array}$ & 4 & 1 \\
\hline JP004 a & 1960 & A Cabeça do Grifo & 2 & 1 \\
\hline $\mathrm{JP004b}$ & 1960 & A Cabeça do Grifo I & 2 & 1 \\
\hline JP005 & 1960 & Episódios & 4 & 0 \\
\hline JP006 & 1960 & Evocação Romântica & 6 & 0 \\
\hline JP013 & 1961 & Sucessões Simétricas I & 1 & 0 \\
\hline JP011 & 1961 & Dois Pequenos Estudos para Aldo Hans & 2 & 0 \\
\hline JP012 & 1961 & Imagens Sonoras & 2 & 0 \\
\hline $\mathrm{JP} 015 \mathrm{a} / \mathrm{b}$ & 1962 & Estrela & 1 & 1 \\
\hline JP016 a & 1963 & Collage & 2 & 0 \\
\hline JP023 & 1964 & Sequência - domino & 4 & 0 \\
\hline JP019 a & 1964 & Dominó & 4 & 0 \\
\hline JP020 & 1964 & Dominó. Struttura & 4 & 0 \\
\hline JP016 b & 1965 & Collage b & 2 & 0 \\
\hline $\mathrm{JP028}$ a & 1966 & Recitativo III & 3 & 0 \\
\hline JP025 & 1966 & Coração Habitado - 1a parte & 3 & 1 \\
\hline JP029 & 1966 & Fascinação & 5 & 0 \\
\hline JP0310a & 1967 & Harmónicos I & 1 & 0 \\
\hline JP037 & 1969 & $\begin{array}{l}\text { Estudo I. Mémoire d'une presence } \\
\text { absente }\end{array}$ & 1 & 0 \\
\hline JP0310b & 1969 & Harmónicos I 2 & 2 & 0 \\
\hline $\mathrm{JP028} \mathrm{b}$ & 1969 & Recitativo III & 3 & 0 \\
\hline JP0410a & 1970 & Estudo II & 1 & 0 \\
\hline JP040 & 1970 & $\mathrm{CDE}$ & 4 & 0 \\
\hline JP044 a & 1970 & As Quatro Estações & 4 & 0 \\
\hline JP048 & 1971 & Récit & 1 & 0 \\
\hline JP049 & 1971 & Recitativo II & 2 & 2 \\
\hline
\end{tabular}




\begin{tabular}{|c|c|c|c|c|}
\hline JP047 c & 1971 & Nocturnal I & 7 & 0 \\
\hline \multirow[t]{2}{*}{ JP047 b } & 1971 & Nocturnal II & \multirow[t]{2}{*}{6} & \multirow[t]{2}{*}{1} \\
\hline & 1971 & Nocturnal II b & & \\
\hline JP0410b & 1972 & Estudo II b & 1 & 0 \\
\hline JP055 & 1972 & Recitativo I & 1 & 0 \\
\hline JP057 & 1972 & Welkom & 2 & 0 \\
\hline JP051 & 1972 & A Lira Destemperada & 2 & 1 \\
\hline JP044 b & 1972 & As Quatro Estações & 4 & 0 \\
\hline JP072 & 1976 & Estudo III em si, maior & 1 & 0 \\
\hline JP074 & 1976 & Solo & 1 & 0 \\
\hline JP070 & 1976 & Canto da Sibila & 3 & 0 \\
\hline JP071 & 1976 & Elegia & 4 & 0 \\
\hline JP069 & 1976 & $\begin{array}{l}\text { A Aurora do Socialismo. Madrigale } \\
\text { Capriccioso }\end{array}$ & 5 & 0 \\
\hline JP076 a & 1977 & Lov & 1 & 0 \\
\hline JP076 b & 1977 & Lov & 2 & 0 \\
\hline JP076 c & 1977 & Lov & 2 & 0 \\
\hline JP076 d & 1978 & Lov I. Canção Sem Palavras & 2 & 0 \\
\hline JP078 & 1978 & Madrigal II & 5 & 0 \\
\hline JP082 a & 1979 & Faites Vos Jeux, Mes Dames Messieurs! & 4 & 0 \\
\hline JP009 III c & 1980 & Ah! A angústia, a raiva vil, o desespero...c & 4 & 0 \\
\hline JP086 & 1980 & Warsaw Workshop Waltz & 4 & 0 \\
\hline JP009 III b & 1980 & $\begin{array}{c}\text { Ah! A angústia, a raiva vil, o desespero... } \\
\text { b }\end{array}$ & 4 & 1 \\
\hline JP009 III d & 1980 & $\begin{array}{c}\text { Ah! A angústia, a raiva vil, o } \\
\text { desespero...d }\end{array}$ & 5 & 0 \\
\hline JP089 a & 1981 & Music Box (esboços) & 1 & 0 \\
\hline JP090 & 1981 & Novo Canto da Sibila & 3 & 0 \\
\hline JP004 c & 1981 & A Cabeça do Grifo II & 3 & 1 \\
\hline JP088 & 1981 & Leves Véus Velam & 3 & 1 \\
\hline JP091 & 1981 & Serenata per A & 4 & 0 \\
\hline JP094 & 1982 & L'Oiseau-Lyre & 1 & 0 \\
\hline JP097 a & 1982 & Sax-Blue & 1 & 0 \\
\hline JP097 b & 1982 & Sax-Blue & 2 & 0 \\
\hline JP097 c & 1982 & Sax-Blue & 2 & 0 \\
\hline JP098 a & 1982 & Ulivi Aspri e Forti I & 1 & 1 \\
\hline JP097 d & 1982 & Sax-Blue & 3 & 0 \\
\hline JP095 & 1982 & Madame Borbolet(r)a & 6 & 0 \\
\hline JP092 a & 1982 & Ciclo-Valsa & 6 & 1 \\
\hline JP076 e & 1983 & Lov II & 3 & 0 \\
\hline JP097 e & 1984 & Sax-Blue & 1 & 0 \\
\hline JP102 & 1984 & Estudo IV. Para uma corda só & 1 & 0 \\
\hline JP105 & 1984 & Red Sweet Tango & 1 & 0 \\
\hline JP097 f & 1984 & Sax-Blue & 2 & 0 \\
\hline
\end{tabular}




\begin{tabular}{|c|c|c|c|c|}
\hline JP092 b & 1984 & Ciclo-Valsa II & 3 & 1 \\
\hline JP103 & 1984 & Greetings, Lied für H. J. K & 4 & 1 \\
\hline JP110 & 1985 & The Missing Miss & 1 & 0 \\
\hline JP089 b & 1985 & Music Box (definitivo) & 1 & 0 \\
\hline JP109 & 1985 & Remake & 4 & 0 \\
\hline JP0310c & 1986 & Harmónicos I 2 b & 4 & 0 \\
\hline JP116 & 1987 & Villalbarosa & 1 & 0 \\
\hline JP114 & 1987 & O Quadrado Azul & 4 & 0 \\
\hline JP115 & 1987 & Sine Nomine & 10 , var. & 1 \\
\hline JP117 & 1988 & $\begin{array}{l}\text { Aquela Tarde. Epitáfio a Joly Braga } \\
\text { Santos }\end{array}$ & 1 & 0 \\
\hline JP122 & 1989 & Passage Intérieur & 5 & 0 \\
\hline JP126 & 1990 & Glosa I & 1 & 0 \\
\hline JP127 & 1990 & Glosa III & 1 & 0 \\
\hline JP128 & 1990 & Glosa IV & 1 & 0 \\
\hline JP124 & 1990 & Cantos de Sophia & 1 & 1 \\
\hline JP125 & 1990 & Fantasia-Impromptu & 2 & 0 \\
\hline JP131 & 1992 & Estudo V. Die Reihe-Courant & 1 & 0 \\
\hline JP134 & 1992 & Glosa II & 1 & 0 \\
\hline JP135 & 1992 & In Folio. Para Contança & 1 & 0 \\
\hline JP136 & 1992 & Nocturno & 1 & 0 \\
\hline JP137 & 1993 & $\begin{array}{l}\text { Nocturno no Cabo do Mundo. Sonata } \\
\text { para } 3 \text { pianos }\end{array}$ & 3 & 0 \\
\hline $\mathrm{JP019b}$ & 1994 & Dominó & 4 & 0 \\
\hline JP138 & 1994 & ... A Silenciosa rosa / Rio do tempo & 5 & 0 \\
\hline
\end{tabular}

Quadro 1: as obras de câmara de J.P.

\section{Instrumentos}

J.P. escreveu para instrumentos muito diversos, incluindo instrumentos como guitarra elétrica, bateria e viola da gamba. Aparecem, também, referências a "instrumentinhos" tocados pelos diversos instrumentistas de instrumentos mais usuais. Trata-se de grupos de instrumentos diversos tais como harmónica de boca, pratos suspensos, crótalos, pequenos instrumentos de percussão e brinquedos/objetos diversos que produzem som. Está também muito presente a eletroacústica - em fita magnética - inserida em cerca de 20 obras de câmara.

Alguns instrumentos destacam-se pelo elevado número de obras que os incluem: piano, percussão, flauta, harpa, voz, clarinete e violoncelo. 


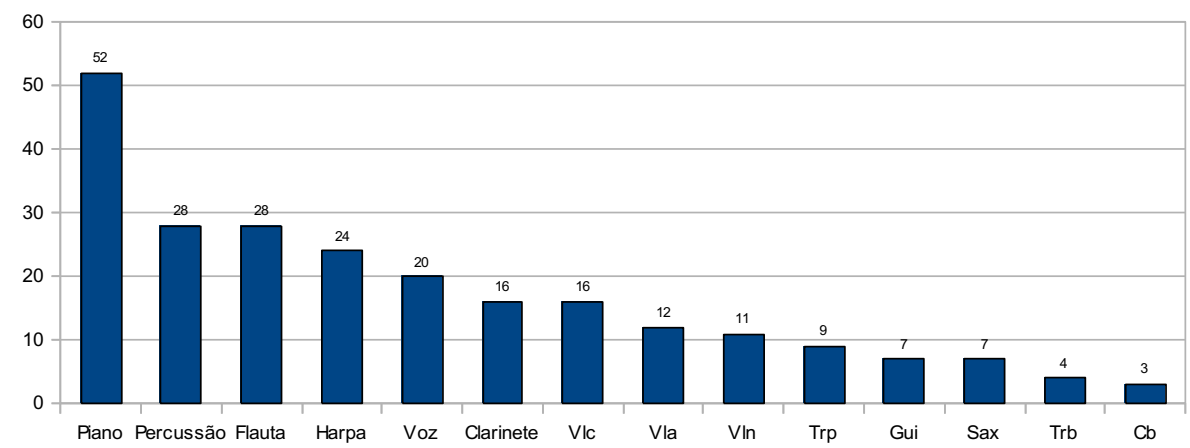

Quadro 2: $\mathrm{n}^{\mathrm{o}}$ de vezes que J.P. utilizou cada instrumento nas obras de câmara

Tendo sido J.P. um pianista profissional com uma carreira que manteve até ao fim da sua vida, é natural que tivesse escrito um grande número de obras usando o seu instrumento. E há, desde logo, um número elevado que somente inclui piano: 18 obras para piano solo, uma para 2 pianos (ou duas, incluindo-se uma versão de Harmónicos para 2 pianos) e uma outra para 3 pianos.

Observa-se, ainda, o elevado número de peças que compôs incluindo instrumentos que os seus amigos e colaboradores mais próximos tocavam: Carlos Franco (flauta), Clotilde Rosa (harpa), Catarina Latino (percussão), António Oliveira e Silva (viola), Luísa de Vasconcelos (violoncelo), Maria João Serrão e Manuela Sá (voz), Lopes e Silva (guitarra), António Saiote (clarinete), etc. (TELLES, 2012). Destacam-se ensembles que contém simultaneamente flauta e harpa (14 peças), 9 contendo piano e violoncelo, 8 contendo piano e flauta, 8 com voz e piano, também 8 com flauta e percussão, 7 com piano e percussão, incluindo as reorquestrações de obras anteriores. Assim se observa, também, o que foi o núcleo duro do G.M.C.L., em especial nos anos de 70 e 80 (TELLES, 2012).

\section{Distribuição ao longo de tempo e número de obras}

A distribuição das obras de câmara ao longo dos anos é bastante equilibrada, com pequenos hiatos onde a produção para maiores grupos está presente (Quadro $3)$.

O ritmo geral de composição teve eventualmente os anos maiores entre 1970 e 1986, havendo nitidamente alguma diminuição a partir deste ano, mais acentuadamente nos anos finais da sua vida, de 1993 até 95. Recorde-se que J.P. começou a exercer atividade docente no Conservatório de Lisboa em 1985, tendo tido problemas graves de saúde nos anos finais da sua vida. 


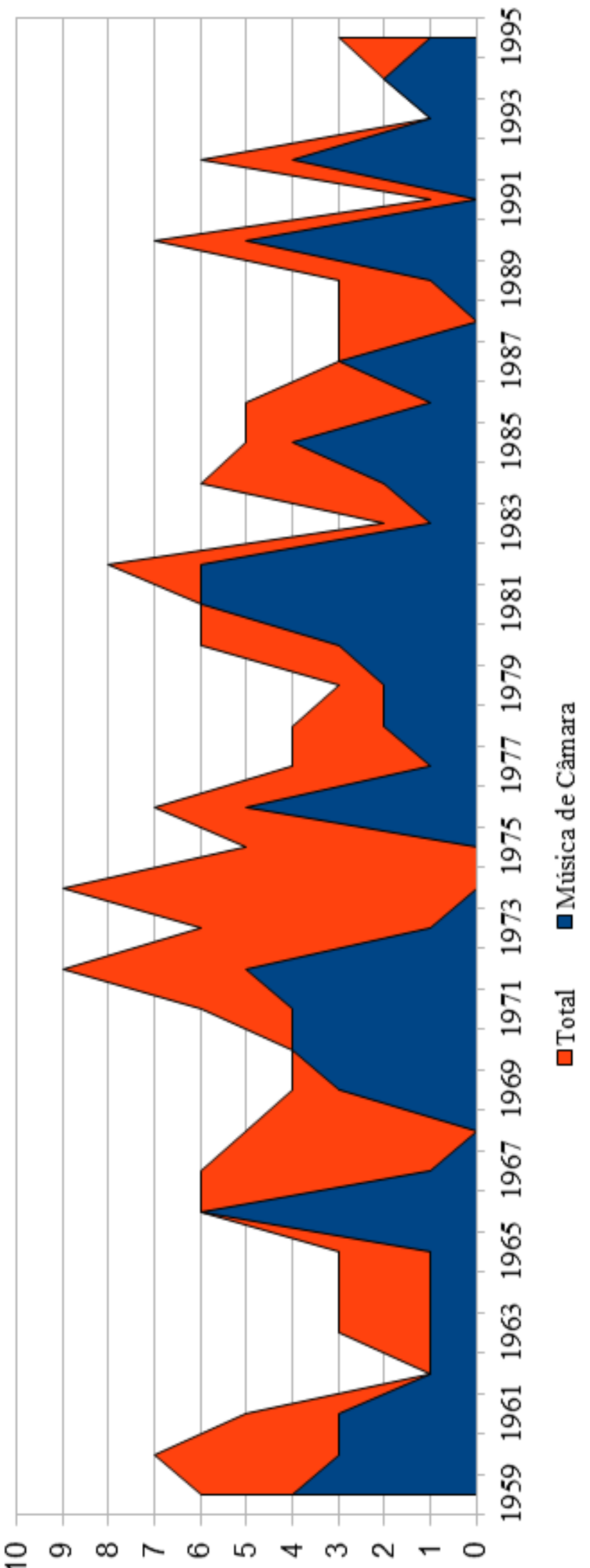

Quadro 3: obras de câmara e total de obras de J.P. 


\section{Revisões, readaptações, transcrições, transformações}

Um grande número de obras sofreu transformações muito diversas: revisões de índole académica (incentivo de professores), revisões um pouco maiores, transposições para outras tessituras, re-instrumentações com nenhumas ou maiores adaptações, aumento de instrumentos, alargamento das peças, recomposição com o mesmo material base, etc.

Não parece haver qualquer complexo ou recusa de obras já com décadas, tendo J.P. as incorporado e adaptado ao seu repertório do momento. Tal se deve, entre outros, à necessidade de voltar a apresentar peças antigas, por vezes ouvidas em público muito poucas vezes, e ainda à necessidade de encontrar obras (ou revisões das mesmas) que renovassem o seu repertório e o do seu Grupo G.M.C.L.

Interessante é, também, o fato de J.P. procurar várias vezes peças bastante mais antigas e transformá-las: dois casos paradigmáticos são a reescrita em 1981 de Cabeça do Grifo (1960) e em 1994 o trabalho com Domino de 1964.

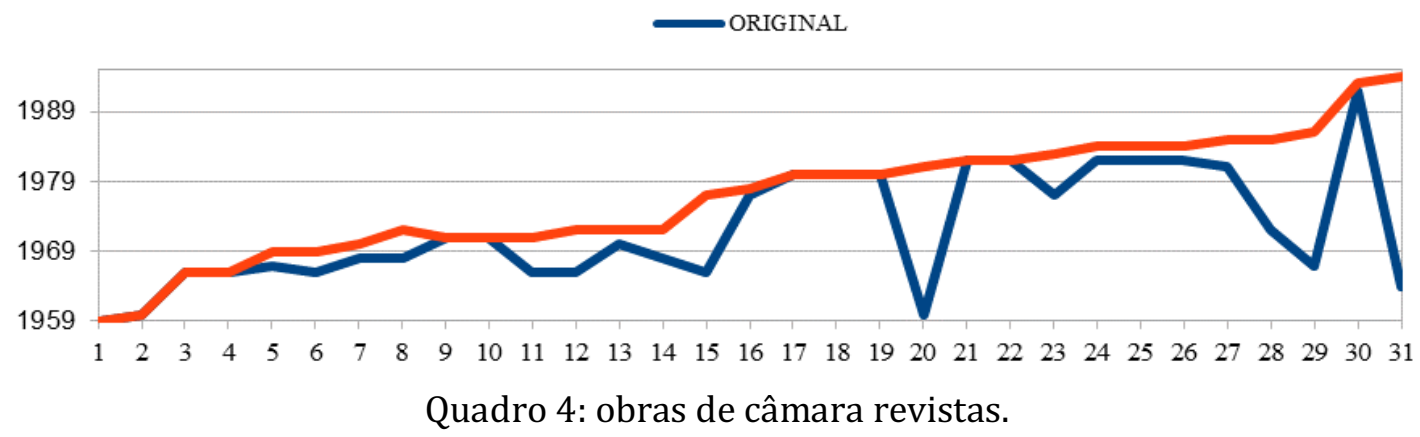

Foram analisados os tipos de revisões das diversas obras, divididos em diferentes categorias:

- Mudança de texto, transposição, re-instrumentação sem alterações;

- Revisão (correções académicas, muito ligeiras correções de escrita e de gestos musicais);

- Ligeiras alterações (alteração completa da orquestração, pequenas alterações de notas e gestos, ornamentação);

- Aumento da peça (maior desenvolvimento do material, acrescento de novo material);

- Reorganização e novo desenvolvimento completo do material. 
20

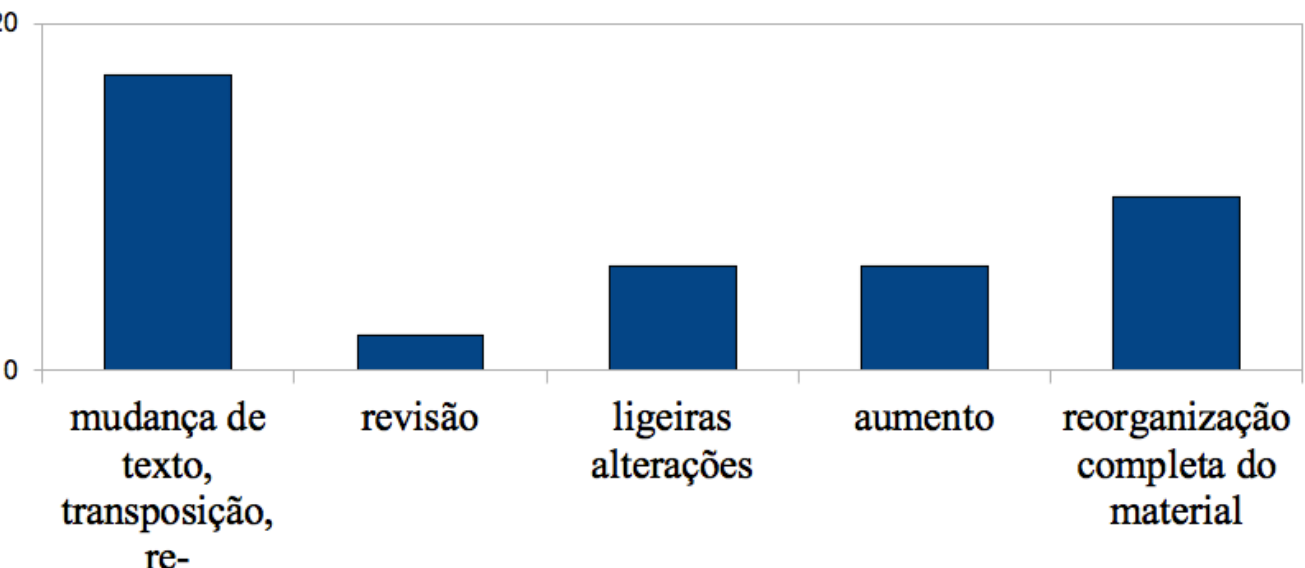

instrumentação

Quadro 5: tipo de revisões.

É nítida a desproporção entre estes diversos aspetos, em especial o elevado número de obras que foi remodelado - recomposto - integralmente e aumentado, mostrando um interesse de J.P. nesta maneira de trabalhar. Lembremo-nos de obras como Sucessões Simétricas I (para piano e depois para orquestra, não incluídas neste estudo de música de câmara), ou então nas obras que derivaram de composições anteriores para música de cena (os diversos Recitativos, Situações 66, Estudo II com

342 versões e Remake, e Lov nas suas 3 versões.

\begin{tabular}{|c|c|c|c|}
\hline ORIGINAL & $\begin{array}{l}\text { DATA DE } \\
\text { REVISÃO }\end{array}$ & NOME & TIPO DE TRANSFORMAÇÃO \\
\hline 1959 & 1959 & Fascinação & mudança de texto para vocalizo \\
\hline 1960 & 1960 & A Cabeça do Grifo I & correções a uma peça académica \\
\hline 1966 & 1966 & Recitativo III & $\begin{array}{c}\text { peça baseada na música de cena para "O gebo e a } \\
\text { sombra" }\end{array}$ \\
\hline 1966 & 1966 & Situações 66 & $\begin{array}{l}\text { a partir da música de cena para "diário de um } \\
\text { louco" }\end{array}$ \\
\hline 1967 & 1969 & Harmónicos I 2 & a mesma proposta para outros instrumentos \\
\hline 1966 & 1969 & Recitativo III & $\begin{array}{c}\text { re-elaboração do material e aumento. Inclui } \\
\text { integralmente "Recitativo I" }\end{array}$ \\
\hline 1968 & 1970 & Estudo II a & $\begin{array}{l}\text { a partir da música de cena para "As Quatro } \\
\text { Estações", de Arnold Wesker. }\end{array}$ \\
\hline 1968 & 1972 & As Quatro Estações & $\begin{array}{l}\text { a partir da música de cena para "As Quatro } \\
\text { Estações", de Arnold Wesker. }\end{array}$ \\
\hline 1971 & 1971 & Nocturnal II & $\begin{array}{l}\text { grande aumento e re-instrumentação (com parte } \\
\text { de voz extra, e flauta b) da versão I (de } 3 \text { páginas } \\
\text { para 9) }\end{array}$ \\
\hline 1971 & 1971 & Nocturnal II b & $\begin{array}{c}\text { versão onde substitui a flauta b por vibrafone, a } \\
\text { viola por clarinete baixo e pequenas rasuras a } \\
\text { lápis }\end{array}$ \\
\hline 1966 & 1971 & Recitativo II & $\begin{array}{c}\text { peça baseada na música de cena para "0 gebo e a } \\
\text { sombra" }\end{array}$ \\
\hline
\end{tabular}




\begin{tabular}{|c|c|c|c|}
\hline 1966 & 1972 & Recitativo I & $\begin{array}{l}\text { peça incluída na música de cena para "O gebo e a } \\
\text { sombra" }\end{array}$ \\
\hline 1970 & 1972 & Estudo II b & re-elaboração completa do material \\
\hline 1968 & 1972 & $\begin{array}{l}\text { As Quatro Estações } \\
\text { (definitiva) }\end{array}$ & $\begin{array}{c}\text { Revisão definitiva de 1970, a partir da música de } \\
\text { cena para "As Quatro Estações", de Arnold } \\
\text { Wesker }\end{array}$ \\
\hline 1966 & 1977 & Lov & $\begin{array}{c}\text { passagem para uma peça para piano de música de } \\
\text { cena "Acto sem palavras", de S. Beckett }\end{array}$ \\
\hline 1977 & 1978 & $\begin{array}{l}\text { Lov I. Canção Sem } \\
\text { Palavras }\end{array}$ & $\begin{array}{c}\text { acrescento de um novo instrumento - flauta - e } \\
\text { re-elaboração/revisão do material. Junção de } \\
\text { uma parte final (citação de "Morte de Isolda", R. } \\
\text { Wagner) }\end{array}$ \\
\hline 1980 & 1980 & $\begin{array}{l}\text { Ah! A angústia, a } \\
\text { raiva vil, o } \\
\text { desespero...c } \\
\end{array}$ & nova instrumentação e adaptação \\
\hline 1980 & 1980 & $\begin{array}{l}\text { Ah! A angústia, a } \\
\text { raiva vil, o } \\
\text { desespero... b }\end{array}$ & nova instrumentação e adaptação \\
\hline 1980 & 1980 & $\begin{array}{l}\text { Ah! A angústia, a } \\
\text { raiva vil, o } \\
\text { desespero...d } \\
\end{array}$ & $\begin{array}{c}\text { nova instrumentação, adaptação e acrescento de } \\
\text { material novo (violoncelo) }\end{array}$ \\
\hline 1960 & 1981 & A Cabeça do Grifo II & nova instrumentação e ligeira adaptação \\
\hline 1982 & 1982 & Sax-Blue & versão com correções \\
\hline 1982 & 1982 & Sax-Blue & $\begin{array}{c}\text { novas versões com mais instrumentos, música } \\
\text { muito semelhante }\end{array}$ \\
\hline 1977 & 1983 & Lov II & $\begin{array}{l}\text { acrescento de um novo instrumento com parte } \\
\text { completamente diferente (novo solo) }\end{array}$ \\
\hline 1982 & 1984 & Sax-Blue & $\begin{array}{c}\text { novas versões com mais instrumentos, música } \\
\text { muito semelhante }\end{array}$ \\
\hline 1982 & 1984 & Sax-Blue & $\begin{array}{l}\text { novas versões com mais instrumentos, música } \\
\text { muito semelhante }\end{array}$ \\
\hline 1982 & 1984 & Ciclo-Valsa II & $\begin{array}{l}\text { re-instrumentação de peça com menos partes } \\
\text { (tempo sempre aleatório) }\end{array}$ \\
\hline 1981 & 1985 & Music Box b & (perdida) \\
\hline 1972 & 1985 & Remake & $\begin{array}{l}\text { reinstrumentação e muito ligeira adaptação de } \\
\text { peça de piano estudo ii b }\end{array}$ \\
\hline 1967 & 1986 & Harmónicos I 2 b & a mesma proposta para outros instrumentos \\
\hline 1992 & 1993 & $\begin{array}{l}\text { Nocturno no Cabo do } \\
\text { Mundo. Sonata para } 3 \\
\text { pianos }\end{array}$ & $\begin{array}{c}\text { adaptação e aumento do material para } 3 \text { pianos } \\
\text { de peça para } 1 \text { piano solo }\end{array}$ \\
\hline 1964 & 1994 & Dominó & (por estudar) \\
\hline
\end{tabular}

Quadro 6: quadro total de revisões

Nota-se, ainda, que alguma tendência inicial por transformações mais profundas pode ter sido preterida a partir de 1980 por outro tipo de transformações menos radicais. 


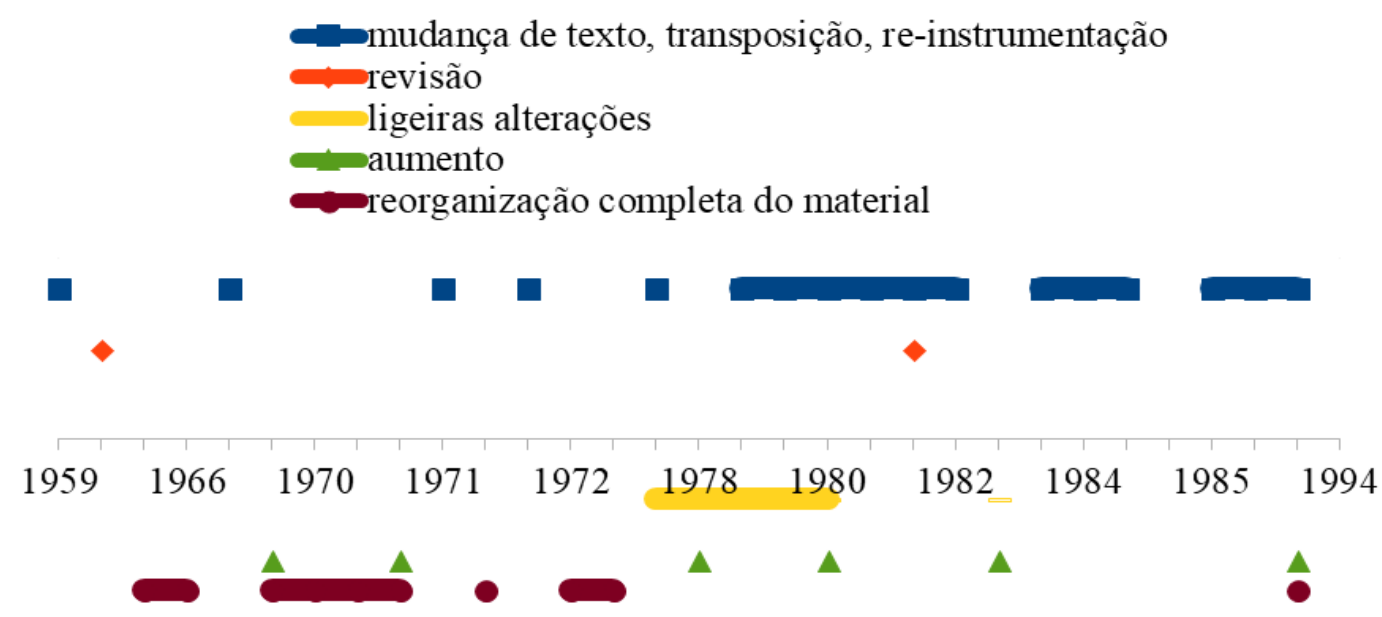

Quadro 7: tipos de revisões ao longo dos anos.

\section{As técnicas usadas}

Na sequência de trabalhos anteriores referentes à música para piano, foi feita uma análise de todas as obras de câmara que, através de parâmetros técnicos e, assim, também estéticos, pudesse refletir uma caracterização das obras e da sua evolução.

Num estudo prévio sobre a música para piano foi utilizada uma tabela de tópicos com as categorizações (não exclusivas) "Utilização de sons experimentais", "Punctilismo/para-serialismo", "Harmonia para tonal", "Repetição" e "Ironia/citação". Os resultados foram interessantes: destacam-se 1 - um interesse muito especial do compositor pela harmonia através do uso de acordes (pós-tonais) encadeados e desenvolvidos noutros semelhantes e 2 - por um certo ecleticismo de técnicas, não havendo tendências relacionadas com o decurso do tempo.

Foi renovado este estudo, agora aplicado às obras de 1 a 5 instrumentos. Os parâmetros foram também aumentados: acrescentaram-se parâmetros métricos ("Métrica repetitiva/medida", "Métrica irregular e muito livre"), foi inserido o uso de "Improvisação" e o uso de elementos "Aleatórios" (que não improvisação), refletindo, neste caso, obras de estrutura aleatória onde o intérprete escolhe o seu caminho por entre as macroestruturas propostas.

\section{Justificação dos parâmetros}


Os diversos parâmetros propostos têm o seu fundamento nas próprias obras de J.P., consistindo, também, em propostas de entendimento estético na maneira como são usadas e compreendidas as técnicas usadas.

\section{Punctilismo/para-serialismo:}

Trata-se, aqui, de um pressuposto técnico com fortes repercussões estéticas, próprio dos anos 50/60 e muito comentado por J.P., tratado em geral como "paraserialismo", com uso de:

a) técnicas próprias do dodecafonismo segundo a 2ª Escola de Viena,

b) de técnicas de permutação com séries de 12 notas,

c) o uso não académico (sem obediência total às regras) de séries de sons, ritmos e dinâmicas diferentes;

Mas também se trata do uso de notas cuja tessitura não configura uma melodia segundo os parâmetros românticos:

a) graus conjuntos e distâncias menores que a oitava como meros fenómenos estatísticos ou contingências instrumentais,

b) alternância entre sons os mais diferenciados possível.

Estes gestos musicais, com um aspeto visual e sonoro característico, são muito comuns ao longo de toda a obra de J.P., mantendo, por vezes, uma certa consistência em termos intervalares e/ou gestuais. Na escrita para piano aparecem desenhos extraordinariamente semelhantes nas obras Sucessões Simétricas (1961) para piano solo, em Estrela para canto e piano (1962), no Estudo I para piano solo (1969), em Serenata per A (1981) para grupo instrumental com piano, em Villalbarosa (1987) para piano solo, e em Glosa 1 também para piano solo (1990).

Destaca-se, no entanto, os anos entre 1980 e 1987, pelo menor interesse do compositor neste tipo de técnicas, aparecendo mais o uso de citações, de harmonias pós-tonais (ou para-tonais) e mesmo da repetição sucessiva de gestos musicais.

\section{Métrica predominantemente repetitiva/medida:}

Trata-se, aqui, do uso de compassos, mesmo que haja para cada compasso um número de tempos diferente. 
Esta atitude métrica de J.P., inicialmente prevalecente, convive, nalgumas obras, com um outro tipo de métrica, mais livre e não medida, correspondendo a uma outra métrica irregular e livre.

\section{Métrica irregular e muito livre:}

A marcação do tempo, neste caso, é por segundos (ou por grupos de segundos), ou também por aproximação a um grafismo da partitura, por vezes sem qualquer barra de compasso ou outra marcação.

Aparece consistentemente a partir de Collage (1963) para 2 pianos, onde uma métrica repetitiva alterna com outras mais livres, e torna-se uma característica da obra de J.P.

\section{Sonoridades experimentais/técnicas alargadas:}

Este critério, talvez já não justificável na qualificação da música de hoje, foi premente no séc. XX. Nos anos 60 a 80 configurou uma pertença estética que remetia para a vanguarda, para John Cage e outros compositores experimentalistas, bem como para o uso informal - em técnicas alargadas - dos instrumentos e das sonoridades.

No caso de J.P. é uma constante ao longo de toda a sua vida, uma característica de muitas das suas obras. Está particularmente presente na obra de 1984 Greetings, Lied für H. J. K, para flauta, fagote, violoncelo, percussão e voz: não existe um texto poético, mas vogais, consoantes, sons de respirações, efeitos com a mão na boca, em geral subtraídos do nome do dedicatário Hans Joachim Koellreutter.

\section{Aleatório:}

Neste estudo o aleatório refere-se:

a) a ser o próprio músico a decidir o percurso interpretativo perante as propostas de J.P., organizando a peça à sua vontade, e

b) a ser o músico a decidir quando tocar a sua parte ou quantas vezes repetir, geralmente em obras de conjunto mais alargado.

Estando presente a partir de Collage para 2 pianos, aparece somente algumas vezes: as diferentes versões de Domino, o Solo para contrabaixo solo, e nas obras de 
ensemble Aurora do Socialismo, Sine Nomine e Ciclo Valsa. Não parece ser uma constante na obra de J.P., embora a sua aparente aproximação estética o fizesse supor.

\section{Ironia/citação:}

Este parâmetro refere-se ao uso de elementos - de gestos - de forte cariz "histórico", com um entendimento estratificado ao longo da história da música, mas inseridos num contexto diferente, atual. Referidos já em Adorno "Quasi una fantasia" (ADORNO, 1982), muito presentes na cultura dos últimos anos (LESSIG, 2008), possuem uma dupla carga enquanto contraste com o presente e enquanto possuidores de um sedimento expressivo histórico. São elementos de diversa ordem, desde citações, emulações de estilos, acordes tradicionais que somente se entendem na sua perplexidade perante o restante material, enfim ironias diversas. Excluem-se as auto-citações, podendo-se confundir estas com elementos (motivos, técnicas) de um estilo pessoal. Alguns são paradigmáticos: o famoso acorde de Tristão, que aparece em múltiplas obras de J.P., o uso de acordes tonais (Si bemol Maior no Estudo III), uso insistente das cordas soltas em The Missing Miss para violino solo, o uso descarado de material tonal em Music Box para piano e 3 caixas de música, na Warsaw Waltz e no Ciclo Valsa para ensemble.

Inicia-se claramente em 1969, - em Lov, para piano e "instrumentinhos", com uma citação do acorde de Tristão, ou então em 1967, com a peça Harmónicos (improvisação para piano sobre notas precisas que formam uma série de harmónicos), aparecendo ao longo de toda a sua obra. Mas a citação do acorde de Tristão aparece-nos já, de forma muito fugaz, nas Sucessões Simétricas I para piano solo, de 1961 (primeiras 4 notas do compasso 24).

\section{Harmonia pós-tonal:}

A harmonia é um elemento fundamental em quase toda a música de J.P.: caracteriza-se pela sucessão de sons simultâneos, em acordes, entendidos estes não na sua acepção de sobreposições de terceiras, mas na consistência da própria simultaneidade; e, em geral, não são o resultado de mais ou menos complexas tramas contrapontísticas. Por vezes estes acordes lembram-nos o sistema tonal, 
outras demonstram uma mera intenção de sucessão harmónica. É uma característica da obra de Jorge Peixinho, aparecendo sobretudo a partir de 1966 (Coração Habitado), mas sendo uma perspectiva da maior importância nas últimas obras do compositor.

\section{Repetição:}

Entende-se aqui a repetição sucessiva de elementos simples (acordes, notas) ou a repetição de um mesmo acorde - ou campo harmónico muito limitado (3, 4 notas) - de maneira persistente, numa passagem de uma obra. A sua audição e reconhecimento são imediatos, embora não tenham geralmente a consistência dos conhecidos minimalistas repetitivos: o minimalismo não parece ser um critério interessante em J.P., nem tão pouco o modalismo destes compositores norte americanos.

A repetição é um elemento contrastante em J.P., marcado pela sua oposição ao serialismo mais tradicional e historicamente sedimentado nos anos 50/60. Aparece claramente pela primeira vez em Harmónicos (1967) e predominantemente 40 entre 1981 e 1987, mas também aparece como repetição de um mesmo som em Sucessões Simétricas I.

\section{Improvisação:}

Este parâmetro refere-se a passagens onde o compositor propõe, de forma mais ou menos controlada, que o músico toque alturas e/ou ritmos à sua escolha, ou que repita com variações improvisadas curtas sequências e gestos musicais. 0 grau de indeterminação do que acontece é elevado, mercê das próprias escolhas individuais dos músicos. A escrita gráfica, presente em algumas (poucas) obras é, também, um incentivo a esta prática.

Na obra de Câmara de J.P. aparece a partir de Harmónicos - obra totalmente improvisada - e também em Estudo I. Mémoire d'une presence absente, mas ainda nos diferentes Recitativos e noutras obras posteriores.

Não sendo um fator marcante na obra de J.P, é também um parâmetro diferenciador. 


\section{Visão global dos parâmetros}

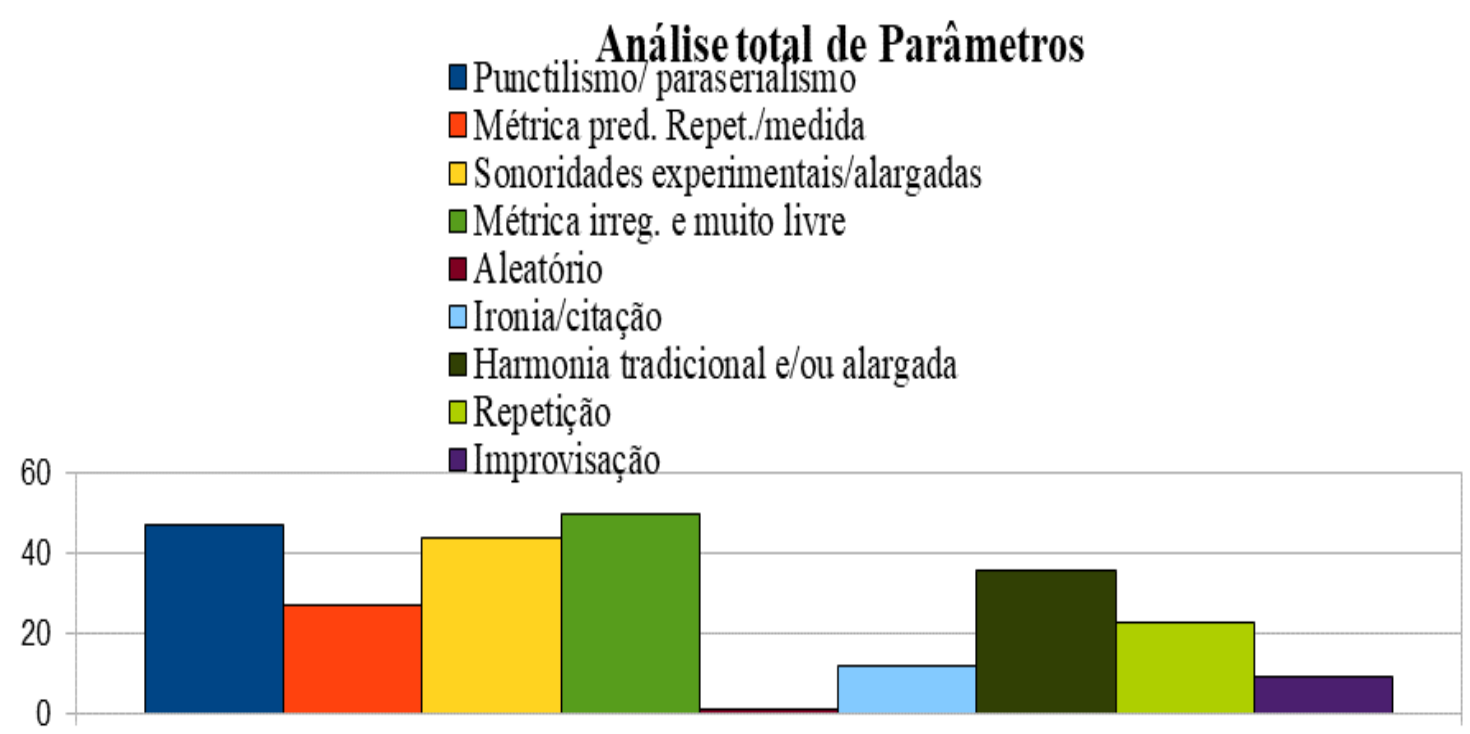

Quadro 8: análise comparativa dos parâmetros.

Uma visão global destes parâmetros mostra a dificuldade de se perceber tendências divergentes em termos técnicos e estéticos.

Parece que J.P. foi-se apropriando de diferentes técnicas, usando-as de uma maneira autónoma relativamente aos pressupostos estéticos inerentes, inserindoas ou não a partir das suas necessidades expressivas. E estas são consistentes através de alguns elementos preponderantes:

1) A preponderância de métricas irregulares, livres;

2) 0 experimentalismo e a informalidade sonora através do uso integral e alargado dos instrumentos;

3) 0 uso daquilo a que J.P. chamou para-serialismo como técnica preponderante, mas não exclusiva, podendo coexistir até na mesma obra com outras técnicas opostas (harmonias diversas, ironia/citação, repetição);

4) A simultaneidade sonora, a harmonia, sempre presente de uma ou outra forma. 


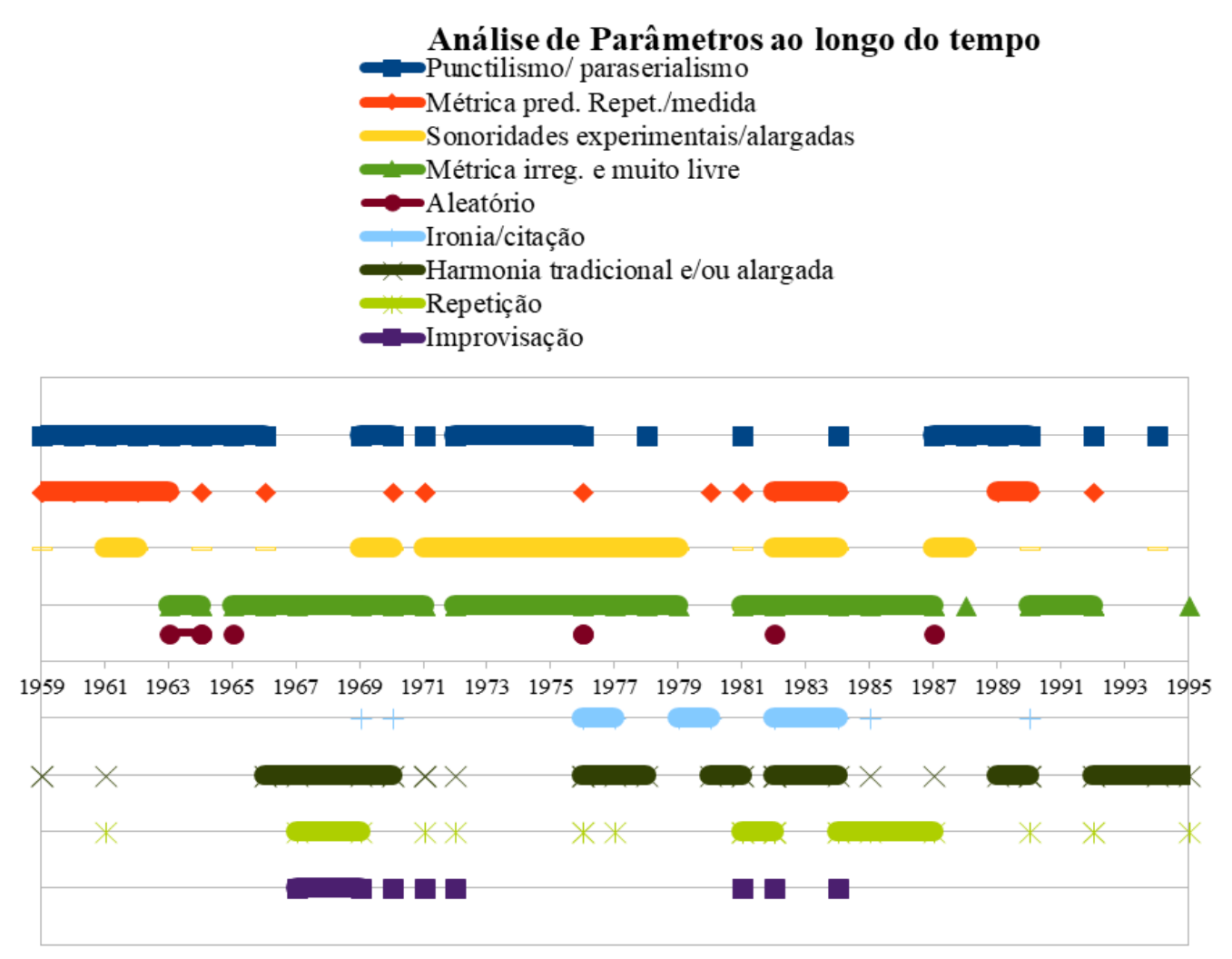

Quadro 9: análise comparativa dos parâmetros ao longo do tempo.

Parece que nos primeiros anos entre 1959 e 1966 as opções de J.P. dirigiramse mais para técnicas dodecafónicas e para-seriais, havendo depois algumas tentativas em aspectos aleatórios (um pouco à imagem da passagem do serialismo integral para estruturas aleatórias em Boulez e Stockhausen); a esta fase corresponde ainda o uso de métricas de índole definida e repetitiva.

A partir de então as métricas mais livres predominam assim como um interesse basilar na harmonia, pontuada aqui e além pela ironia/citação, usando ainda a repetição e, mais esparsamente, a improvisação. Em ...Silenciosa Rosa/Rio do tempo (datada maio de 1994), para flauta, trio de cordas e harpa, J.P. utiliza material harmónico e melódico presente em também em Nocturno para piano solo, de 1992, destacando-se a persistência (mesmo obsessiva) em acordes que se vão encadeando e modificando, pontuados por outros elementos de cariz melódico, tímbrico e rítmico. Igualmente na obra Passage Intérieur (datada 18 de setembro de 1989), para saxofone, guitarra elétrica, guitarra baixo, sintetizador, percussão e banda magnética, J.P. desenvolveu a sua música a partir de um contínuo harmônico 
pontuado por elementos muito diversos, próprios das características idiomáticas dos instrumentos.

\section{Conclusão}

Alguns pontos parecem ser relevantes num resumo deste estudo:

- J.P. não se inibiu em rever obras anteriores - mesmo antigas - no seu catálogo, retomando-as com maiores ou menores alterações;

- O material musical nas obras de J.P. circula livremente entre peças e entre épocas diferentes, aparecendo gestos punctilísticos semelhantes em diferentes peças, passagens semelhantes retomadas em obras de conjunto (p. ex. Warsaw Waltz, Sine Nomine, Ciclo-Valsa, Glosas);

- A persistência ao longo das suas obras de câmara de 4 dos parâmetros analisados - métrica livre, sonoridades experimentais, para-serialismo, harmonia pós-tonal;

- A coexistência, na mesma obra, de parâmetros opostos em termos históricos e estéticos;

- 0 uso de diferentes técnicas fugindo a perspectivas estéticas (filiações estéticas/históricas) mais rígidas: o uso não minimalista das repetições, o para-serialismo, a harmonia pós-tonal, a ironia e a citação, a coexistência de técnicas opostas.

O monolitismo estético das correntes da vanguarda histórica, protagonizadas por Darmstadt dos anos 50 e 60, ou pelo experimentalismo de John Cage e descendentes, não é uma marca de J.P.; talvez estas correntes, da maior importância na sua formação técnica e estética, sejam um lugar de revisitação constante, numa crítica persistente sobre a criação contemporânea e a sua função social e estética, mas não se afiguram como únicas no panorama da música de câmara de J.P., ou sequer numa parte dele. E é interessante que J.P., como músico, persistiu em mostrar, durante toda a sua carreira, obras de John Cage e de outros compositores, numa atitude de choque a um público mais conservador: o J.P. músico teria uma função sociocultural determinante, enquanto o J.P. compositor teria pulsões criadoras autónomas, nem sempre coincidentes com essa vertente ética. 
A ideia de que existe um desvio, uma nova tendência na obra de J.P. a partir de determinada altura (meados de 60? anos 80?), eventualmente mais lírica, mais expressiva, eventualmente neorromântica ou pós-moderna, parece não ter justificação nas obras de câmara; percebe-se, desde cedo, o crescente interesse do compositor por técnicas tais como a repetição, a ironia, e a harmonia pós-tonal.

O ecletismo próprio de outros compositores como Filipe Pires (1934-2015), onde as diversas técnicas coexistem em obras diferenciadas, não é também característica de J.P.: poucas são as obras - e caracteristicamente experimentais e/ou académicas - que se podem filiar claramente numa corrente técnica/estética precisa; entre estas evidenciam-se obras até 1963, ano das primeiras Collage, tendo o compositor apenas 23 anos.

Assim, parecem não ter justificação divisões do total das obras de J.P.: saliente-se uma persistência nos mesmos parâmetros e na mesma forma de inclusão de diferentes técnicas/lugares estéticos, em especial depois de 1967 (data de Harmónicos I, ainda no jovem J.P.). Também a ideia de que as Collage para 2 pianos teriam um carácter pontual e/ou académico parece carecer de alguma revisão: embora algo monolítica em termos estéticos, esta obra de 1963 é o primeiro momento onde, para além do serialismo e para-serialismo característico, J.P. inclui métricas livres e processos aleatórios. De igual maneira muitas das tendências mais expressivas, harmónicas, ou mesmo a citação de Wagner, aparecem já em Sucessões Simétricas I, de 1961, quando J.P. era ainda um jovem de 21 anos.

Característico de J.P. é, assim, a procura de uma linguagem sincrética, que englobe criticamente diferentes técnicas, ironizando com as mesmas a par e passo, ironizando consigo mesmo nas autocitações e na circulação do material em diversas peças ao longo da sua vida, não perdendo a ideia fulcral de uma música atuante esteticamente e, a partir daí, também socialmente. Sendo algumas passagens de obras eventualmente chocantes para um público mais rígido, essas mesmas obras são, em geral, extremamente atuantes expressivamente, procurando tocar o seu público de uma maneira imediata: esse choque parece ser, também, mais um momento expressivo, uma outra maneira de atuar expressivamente no receptor.

A obra de câmara de J.P., aqui analisada, é característica de um percurso criativo com fortes intencionalidades estéticas e éticas, um projeto pessoal que o 
compositor foi construindo de maneira consistente e esclarecida, observando e criticando o mundo em redor, usando criteriosamente os meios expressivos que foi conhecendo, respondendo muitas vezes a pulsões as mais diversas, onde não se excluem as ligadas à paixão amorosa (CARVALHO, 1998). A obra de câmara de J.P. nos remete para um mundo diferente, com pouco lugar para vanguardas, pósmodernismos ou quaisquer outros lugares estéticos estritos, um mundo de procura e afirmação de liberdade, que carece, ainda, de renovados intérpretes, de renovados estudos e de renovados públicos.

\section{Referências bibliográficas}

ADORNO, Theodor W. Quasi una fantasia, Ecrits Musicaux. Paris: Gallimard, 1982.

ASSIS, Paulo (Org.). Mémoires-Miroirs - Conferências do Simpósio Internacional Jorge Peixinho, Lisboa. Lisboa: Colibri, 2012.

BORGES, Cláudia. O Estilo Composicional de Jorge Peixinho nas obras Recitativo I, II, III, IV. Dissertação de Mestrado, Universidade de Aveiro DeCA, Aveiro, 2005.

CARVALHO, Mário Vieira de. Mémoire d'une présence absente, Zur Kritik der Dichotomie zwishen Teleologie und Zuständlichkeit in der Musik als geschlechtsbezogene Kategorien,. In: Abschied in die Gegenwart - Teleologie und Zuständlichkeit in der Musik. [s.l.]: Universal Edition, 1998, v. 35. (Studien zur Wertungsforschung).

C.E.S.E.M., Projeto Jorge Peixinho-Obras de; PEIXINHO, Jorge; MONTEIRO, Francisco. Jorge Peixinho "Chamber Works": Edição Crítica das Obras de Câmara. Jorge Peixinho - Obras de Câmara "Chamber Works". Disponível <http://projectojp.blogspot.com/2012/06/jorge-peixinho-edicao-critica-das-obras.html>. Acesso em: 12 jun. 2018.

DELGADO TEIXEIRA, Cristina. Música, estética e sociedade nos escritos de Jorge Peixinho. Lisboa: Edições Colibri, C.E.S.E.M., 2006.

GUIMARÃES, Paula; AZGUIME, Miguel. Centro de Investigação \& Informação da Música Portuguesa. Disponível em: $<$ http://mic.pt/dispatcher?where=3\&what=2\&show=1\&pessoa_id=142\&lang=PT $>$. Acesso em: 10 jun. 2018.

LESSIG, Lawrence. Remix: making art and commerce thrive in the hybrid economy. New York: Penguin Press, 2008.

MACHADO, José (Org.). Jorge Peixinho - In Memoriam. Lisboa: Caminho, 2002.

MONTEIRO, Francisco. A voz na música de Câmara de Jorge Peixinho. In: BENETTI, Alfonso; CORREIA, Jorge; PESTANA, Maria; et al (Orgs.). PERFORMA'15: International Conference on Music Performance. Proceedings. Aveiro: UA Editora, 2015, p. 153-159.

MONTEIRO, Francisco. Jorge Peixinho: Towards an Ethics of the Avant-garde. In: STÖCK, Gilbert; CASTRO, Paulo Ferreira de; STÖCK, Katrin; et al (Orgs.). "Estes Sons, esta 
Linguagem": Essays on music, meaning and society: in honour of Mário Vieira de Carvalho. Leipzig: Gudrun Schröder Verlag, 2015, p. 399-412.

MONTEIRO, Francisco. The Portuguese Darmstadt Generation: The Piano Music of the Portuguese Avant-Garde. PhD Thesis, Sheffield - dep. music, Sheffield, 2003.

PASCOAL, Maria Lúcia. Momentos de Jorge Peixinho no Brasil. In: ASSIS, Paulo (Org.). Mémoires... Miroirs: Conferências do Simpósio Internacional Jorge Peixinho. Lisboa: Colibri, 2012, p. 175-180.

PEIXINHO, Jorge. Cinco Pequenas Peças, Sucessões Simétricas, Estudo I, Estudo II, Estudo III, para piano. Lisboa: Musicoteca, 1999. (XX-XXI Partituras).

PEIXINHO, Jorge. Glosa I - piano solo. Póvoa de Varzim: Quantitas, 2004.

PESSANHA DE MENEZES, Francisco. Jorge Peixinho: um compositor Português como ponte entre a América latina e os países de expressão ibérica. In: Sevilha (Espanha): Academia.edu, $2016 . \quad$ Disponível em: <https://www.academia.edu/22936485/Jorge_Peixinho_um_compositor_portugu\%C3\%A As_como_ponte_entre_a_Am\%C3\%A9rica_latina_e_os_pa \%C3\%ADses_de_express $\%$ C3\%A 3o_ib\%C3\%A9rica>. Acesso em: 14 ago. 2018.

TAVEIRA, Pedro. Greetings. a canção sem palavras. In: GuimaraMus 2012. Sociedade Musical de Guimarães e Universidade do Minho, Guimarães, 23 a 25 de março de 2012.: [s.n.], 2012.

TEIXEIRA, Cristina Delgado; ASSIS, Paulo. Jorge Peixinho: escritos e entrevistas. Porto: CESEM : Casa da Música, 2010.

TELLES, Ana. 0 Grupo de Música Contemporânea de Lisboa e a criação musical portuguesa. 46 In: ASSIS, Paulo (Org.). Mémoires-Miroirs - Conferências do Simpósio Internacional Jorge Peixinho. Lisboa: Colibri, 2012.

ZOUDILKINE, Evgueni. Alguns aspectos da escrita musical de Jorge Peixinho. In: MACHADO, José (Org.). Jorge Peixinho - In Memoriam. Lisboa: Caminho, 2002.

Centro de Investigação \& Informação da Música Portuguesa. Disponível em: $<$ http://mic.pt $/$ dispatcher?where $=3 \&$ what $=2 \&$ show $=1 \&$ pessoa_id $=142 \& l a n g=P T>$. Acesso em: 10 jun. 2018. 